\title{
Greeks hope crisis may spark reform
}

Financial troubles could be the stimulus for a fairer distribution of science research funding.

As Greece teeters on the edge of bankruptcy, austerity measures are already hitting researchers hard in their pockets. But their labs will be buffered by a huge reserve of European Union (EU) structural funds - subsidies for poor regions - already earmarked for research. And Greek research leaders think the crisis could help shake up a system they say emphasizes security over excellence.

As part of a national package of emergency measures, Greek scientists' pay was cut by around 10\% in March. Institutional research funding, already among the lowest in Europe, was slashed by around $15 \%$. Further cuts are now on the cards after Greece signed a financial bail-out deal with the EU and the International Monetary Fund on 2 May.

Hiring of new staff has mostly stopped. "Lower salaries make Greece even less competitive, and even Greeks abroad may be less tempted to come home," says George Kollias, the director of the Alexander Fleming Biomedical Sciences Research Centre in Vari.

But research leaders hope that the financial crisis will ultimately help them to push through much-needed reforms. "We are not going to sit and cry," says George Thireos, a research director at the prestigious new Bioacademy in Athens. "The crisis here is an opportunity to restructure science policy in Greece, to make better use of low budgets."

At the forefront of the reform effort is Achilleas Mitsos, recently appointed general secretary for research and technology (see go.nature.com/hIga1J). He is planning legislation that will establish research councils and introduce evaluation at all levels, with funds distributed according to performance. Initial resistance

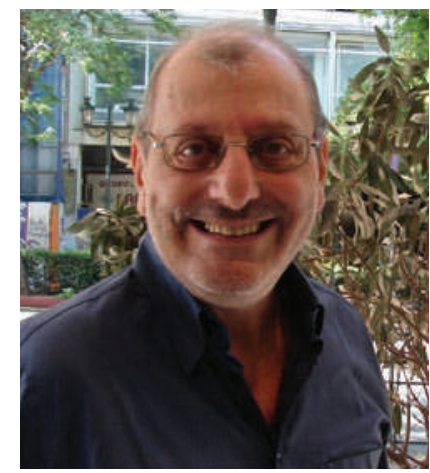

Achilleas Mitsos hopes to establish research funding councils and competitive grants in Greece. compensate for most of the institutional austerity cuts, he says, adding that the funds "will all be distributed through competition". He says that he will announce a call for infrastructure proposals imminently; a call for postdoctoral fellowships in June; and calls for strategic research programmes around October. All applications will have to be in English, and "we will do as much as possible to impose peer review to the highest standard on these calls", he says.

to the changes from researchers comfortable with an undemanding civil-service life has dwindled in the face of the economic crisis.

Mitsos says that he will "spend fast" the $€ 1.5$ billion (US\$2 billion) pot of EU structural funds, made available to Greece for the 200713 period but which are so far untouched. Any money remaining by the end of 2013 must be returned to Brussels. He will tap $€ 300$ million to $€ 400$ million of these funds each year for the next three years. This will financially
The EU-funded plans offer more support than has been available in the past five or six years, when the Greek government did not make any major calls for research proposals, says physicist Costas Fotakis, director of the Institute of Electronic Structure and Laser in Heraklion. "If they really are realized quickly, they will dispel the negative cloud that the general atmosphere has cast over us," he says.

Alison Abbott

\section{European funding may get simpler}

Too many top scientists avoid applying for funds from the European Union (EU) framework research programmes because they can't stand the bureaucracy involved, says EU research commissioner Máire Geoghegan-Quinn.

European research funding should be based on trust, she says. So last week she unveiled a plan that would reduce the detailed accounting demanded by the current funding system,

collaborations created by EU research projects, which require partnerships across different countries and tackle problems relevant to EU policies, such as health and energy. But the red tape is extreme.

which releases funds bit by bit as project milestones are met. She hopes to win approval from the financially risk-averse European Parliament and the Council of the European Union for the rule changes, which would award funds in lump sums with only a single audit. The changes would take effect with the next big EU funding round, the Eighth Framework Programme (FP8), which is due to start in 2014.

Scientists in Europe enjoy the imaginative
"Simplification will not compromise good financial management." existing rules. But scientists must still show how their research plans affect diverse EU policies, from gender issues to innovation. They must also define numerous milestones, and estimate how many months each participant will need for his or her part in achieving them - estimates that must be revised every year, when all money spent has to be accounted for, and any deviations from the plan have to be re-costed and justified.

If framework projects could be funded with a lump sum it would transform the whole programme, says neuroscientist Gilles Pourtois from the University of Ghent in Belgium. In 2008, Pourtois won a prestigious Starting Grant from the European Research Council, which awards generous individual grants, but he has so far avoided framework programmes, which he says are overwhelming. He would, however, apply for FP8 funding if the process were simplified.

The complexity of the framework programmes is partly a result of precautionary auditing measures instituted after a 1999 corruption scandal involving the then research commissioner Edith Cresson. GeogheganQuinn, a former member of the European Court of Auditors, insists that simplification will not compromise good financial management provided that the final audits are sound - and will not increase the risk of fraud.

Alison Abbott 